\title{
Gender Bias and Stereotypes in Medicine: A Medical Student Experience
}

Sofia Jezzini-Martinez,, Daniela C. Conzalez-Cruz. ${ }^{1}$

\begin{abstract}
The Experience
Introduction

Gender bias is a universal phenomenon. Men are seen as the human default and the generic masculinity is embedded in human society. ${ }^{1}$ It exists at home, at school, in the workplace, and its omnipresence originates consequences that have a lasting social and economic impact. ${ }^{1-2}$ Up until the year 1903, no woman had ever won a Nobel Prize, and it was until 1990 that women in science -and specifically women in medicine- began to increase exponentially.3-4 Despite these emerging scientific, social, and cultural changes, gender discrimination remains prevalent.
\end{abstract}

\section{Student Experience}

Since I entered medical school, I knew that I could run the risk of facing comments or situations in which being a woman was considered a disadvantage. Especially since one of the specialties that interested me the most was trauma surgery - a field that is well known for sexist behavior and gender discrimination. 5

As I progressed, my interests changed, and the world of psychiatry became my passion and main area of interest. However, I never imagined what would happen a few years later.

In spring 2021, I began the fourth year of my career in a Mexican medical school with a six-year program. At the end of the semester, our assigned doctor asked the group some questions to get to know each other better and learn about our interests in the future. When he found out I was interested in becoming a psychiatrist, he explained that psychiatry is not a specialty for women. According to him, being in a consult and listening to a patient who is hysteric or depressed is emotionally exhausting, and for a woman, it would be very difficult to spend the whole day listening to patients complain and then go home to take care of her children. He also explained that at least in our institution, psychiatry is a department of men -since the majority of teachers and resident trainees are male. At that moment, I was shocked and struggled with how to react, so I only replied that psychiatry was still my main interest.

Living through that situation, I concluded that we could never cater to everyone's opinions, which reinforced my decision to follow my interests regardless of others' prejudices about my gender. However, several questions arose in my mind: What impact did this situation have among my colleagues and classmates - male and female- who were present? Had they identified the discrimination? What if his comment had been influential enough to cause me not to pursue my dream (or others') of becoming a psychiatrist?
After a few days, I discussed this situation with some of my female colleagues, and I was disappointed to discover that more than one had gone through similar situations. This led us to conclude the importance of eliminating gender stereotypes and opportunity biases within the medical area.

\section{Possible Solutions}

Raise awareness

Stone et al. (2020) write about distinguishing benevolent from hostile sexism. The latter is easier to identify since it consists of hostile behaviors based on gender, whereas the former is associated with elements such as patronizing women and gender stereotypes -women are seen as kinder, therefore, they should focus on "softer specialties".5 We propose the inclusion of topics such as gender-based discrimination in the medical curriculum and to assess its impact not only on health workers but on the community, as well.

Another solution is to implement medical training that focuses on differences in presentation, diagnosis, and treatment of diseases between sexes to achieve better outcomes; especially since evidence has shown that significant differences do exist in the presentation and management of diseases such as myocardial infarction, Alzheimer's disease, and others. If our gender makes us so different, why are we teaching our doctors to diagnose and treat men and women the same? ${ }^{\text {6-7 }}$

Figure 1. Possible Solutions to Address Gender Bias and Stereotypes in Medicine.

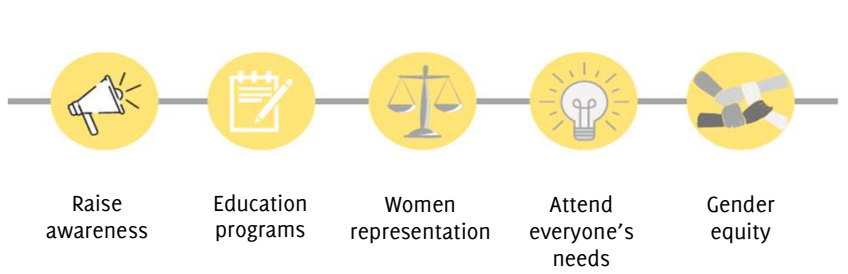

Education programs

Discrimination has also been reported by health care professionals of different minority groups such as the LGBT community and people of color who face social ostracization, discriminatory treatments, and workplace harassment. ${ }^{8-10}$ Educational programs that involve all male and female medical students, faculty, and staff led by the institutions, which address gender bias, discrimination, and stereotypes in medicine and academia, need to be implemented. These programs should not only include testimonies and activities based on experiences to help students and physicians identify implicit gender bias and discrimination

1 Universidad Autónoma de Nuevo León, Monterrey, Mexico.

About the Author: Sofía Jezzini-Martínez is a fourth-year medical student of a six-year program. She is member of the Anatomy research group in the Department of Human Anatomy, School of Medicine at the Universidad Autónoma de Nuevo León, Monterrey, Nuevo León, México. She currently works on several research projects oriented towards bone and joint, psychiatry, and medical education.

Correspondence:

Sofia Jezzini-Martinez

Address: Universidad Autónoma de Nuevo León, Monterrey, Mexico. Email: sofiajezzini@gmail.com
Editor: Francisco J. Bonilla-Escobar Student Editors: Mohammad Amin Khazeei Tabari O Hang-Long (Ron) Li Copyeditor: Nguyen Tran Minh Duc Proofreader: Anna-Maria Chantaliyska Layout Editor: Sushil Dahal
Submission: Sep 6, 2021 Revisions required: $\operatorname{sep} 8 ; \operatorname{sep} 24,2021$ Received in revised form: Sep 13: Sep 282021 Acceptance: Sep 29, 2021 Publication: Sep 30, 2021 Process: Peer-reviewed 
in real-life situations, but also evidence-based anti-sexist training to achieve the skills to remove systems that continue to perpetuate inequity . ${ }^{11}$ Empathizing with the discrimination experiences could drive efforts to create respectful and fair workplaces for physicians. ${ }^{2}$

\section{Attend the Needs of Everyone}

Investigate what female students, resident trainees, and doctors need to have a more comfortable and advantageous experience within their institution - that is their medical school and hospital. Develop new policies and study their impact. Amir Ali (2015) studied the gender differences in the acquisition of surgical skills, proving that male and female medical students differ in their visuospatial abilities and gaming experience, but providing females with instructor feedback and training seems to eliminate these differences. ${ }^{12}$ Another action that could help address everyone's needs is implementing childcare services in schools and hospitals to facilitate and promote healthy and inclusive parenting models among doctors.

\section{Women Mentorship and Representation}

In the recent Netflix documentary "Picture a Scientist", Dr. Raychelle Burks of American University in Washington, D.C., recalls that as a child, her female scientist role model was a fictional character. We need to increase female role models in teaching, mentorship, and research.
Discrimination against women limits the representation of half of the population and their scientific advances avoiding the creation of more inclusive environments that could have implications for the care we provide to patients. ${ }^{2}$

Including more women in decision-making and policy-making positions promotes equity among representative and directive committees. A way to achieve equity in committees and departments is the implementation of policies that encourage setting a minimum limit on the number of females recruited each year to balance out the male: female ratio.

\section{Conclusion}

Today we are the ones who are behind the desk, but tomorrow we will be doctors, mentors, and researchers who will transmit knowledge and different perspectives to students, forging them as future specialists. It is important that we, as a society, educate ourselves in identifying stereotypes and gender-biased situations to eliminate gender discrimination in science. We need to understand that both male and female doctors are free to choose to practice the specialty they wish to without being questioned, criticized, and discouraged for wanting to stand out.

\section{References}

1. Perez CC. Invisible women: Exposing data bias in a world designed for men. Random House, 2019.

2. Rotenstein LS, Jena AB. Lost Taussigs - The Consequences of Gender Discrimination in Medicine. N Engl J Med. 2018 Jun 14;378(24):2255-2257.

3. Charyton C, Elliott JO, Rahman MA, Woodard JL, Dedios S. Gender and science: Women Nobel laureates. J Creat Behav. 2011 Dec 22;45(3): 203-214.

4. Schiebinger L. The mind has no sex?. Women in the origins of modern science. Harvard University Press, 1991.

5. Stone L, Phillips C, Douglas KA. With the best will in the world: How benevolent sexism shapes medical careers. Med Educ. 2020 Feb;54(2):94-97.

6. Liakos M, Parikh PB. Cender Disparities in Presentation, Management, and Outcomes of Acute Myocardial Infarction. Curr Cardiol Rep. 2018 Jun 16;20(8):64

7. Nebel RA Aggarwal NT, Barnes LL, Gallagher A, Goldstein JM, Kantarci K, et al. Understanding the impact of sex and gender in Alzheimer's disease: A call to action. Alzheimers Dement. 2018 Sep;14(9):1171-1183.

8. Peterson NB, Friedman RH, Ash AS, Franco S, Carr PL. Faculty self-reported experience with racial and ethnic discrimination in academic medicine. I Cen Intern Med. 2004 Mar;19(3):259-65.

9. Ko $\mathrm{M}$ and Dorri A. Primary care clinician and clinic director experiences of professional bias, harassment, and discrimination in an underserved agricultural region of California. JAMA Netw Open. 2019 Oct 2;2(10):e1913535.

10. Lu DW, Pierce A, Jauregui J, Heron S, Lall MD, Mitzman J, et al. Academic Emergency Medicine Faculty Experiences with Racial and Sexual Orientation Discrimination. West J Emerg Med. 2020 Aug 21;21(5):1160-1169.

11. Morgan AU, Chaiyachati KH, Weissman CE, Liao JM. Eliminating Gender-Based Bias in Academic Medicine: More Than Naming the "Elephant in the Room". J Gen Intern Med. 2018 Jun;33(6):966-968.

12. Amir $A$, Subhi $Y$, Ringsted $C$, Konge $L$, et al. Cender differences in the acquisition of surgical skills: a systematic review. Surg Endosc. 2015 Nov;29(11):3065-73.

\section{Acknowledgments}

None

\section{Conflict of Interest Statement at Funding}

The Authors have no funding, financial relationships or conflicts of interest to disclose.

\section{Author Contributions}

Conceptualization, Data Curation, Investigation, Methodology, Project Administration, Resources, Supervision, Validation, Visualization, Writing - Review at Editing: SJ, DCG; Writing - Original Draft Preparation: SJ.

Cite as

Jezzini-Martinez S, Gonzalez-Cruz DC. Gender Bias and Stereotypes in Medicine: A Medical Student Experience. Int J Med Students. 2021 0ct-Dec;9(4):310-1.

This work is licensed under a Creative Commons Attribution 4.0 International License

ISSN 2076-6327

This journal is published by the University Library System, University of Pittsburgh as part of the Digital Publishing Program and is co-sponsored by the University of Pittsburgh Press. 